\title{
Apps on Google Play Store to assist in self-management of hypertension in Indian context: features analysis study
}

\author{
Mahima Kaur ${ }^{1 \wedge}$, Harpreet Kaur ${ }^{1 \wedge}$, Surbhi Rathi ${ }^{1,2}$, Manikyarao Ashwitha $^{1,2}$, Jenifer Joanna ${ }^{1,2}$, \\ Srinitya Reddy $^{1,2}$, Batul Idris ${ }^{1,2}$, Persis Myrtle ${ }^{1,2}$, Sarvani Kandamuru ${ }^{1,2}$, Sara Fatima ${ }^{1,2}$, Ashish Joshi ${ }^{3 \wedge}$ \\ ${ }^{1}$ Foundation of Healthcare Technologies Society, New Delhi, Delhi, India; ${ }^{2}$ Department of Nutrition, St. Ann's College for Women, Hyderabad, \\ India; ${ }^{3}$ CUNY Graduate School of Public Health and Health Policy, City University of New York, New York, NY, USA \\ Contributions: (I) Conception and design: A Joshi; (II) Administrative support: A Joshi; (III) Provision of study materials or patients: None; (IV) \\ Collection and assembly of data: M Kaur, H Kaur, S Rathi, M Ashwitha, J Joanna, S Reddy, B Idris, P Myrtle, S Kandamuru, S Fatima; (V) Data \\ analysis and interpretation: M Kaur, H Kaur; (VI) Manuscript writing: All authors; (VII) Final approval of manuscript: All authors. \\ Correspondence to: Ashish Joshi, PhD, MBBS, MPH. Senior Associate Dean Academic and Student Affairs, CUNY Graduate School of Public Health \\ and Health Policy, City University of New York, 55 W 125th St., New York, NY 10027, USA. Email: ashish.joshi@sph.cuny.edu.
}

\begin{abstract}
Background: A large number of individuals with hypertension are turning to the Internet and m-health technologies for assistance. There is a need to study the content of smartphone applications on hypertension. The study aimed to review and investigate the functional and analytical characteristics of apps related to the self-management of hypertension available on Google Play Store.

Methods: Search was conducted in February 2021 in India using the Google Play Store database to identify currently available Android-based apps related to self-management of hypertension/high blood pressure (BP). Keywords used were: 'Hypertension', 'High blood pressure', 'DASH diet', 'Hypertension diet', and 'Blood pressure diet'. A total of 822 apps were screened based on the duplicates, inclusion, and exclusion criteria. A total of 210 were included for further analysis.

Results: Eighteen percent ( $n=37$ ) of the apps had an overall rating of 4.5 or above. About $41 \%$ of the apps belonged to the medical category and $41 \%$ of the apps were characterized in the health and fitness category. Feature of logging/recording the BP measurement was seen in $73 \%$ of the apps. In-app graphing to analyze BP trends was reported in $64 \%$ of the included apps. A few apps focused on tracking medication $(n=19)$, sodium intake $(n=2)$, and calorie intake $(n=4)$.

Conclusions: The features were common across all the included apps and were focusing only on recording the BP, providing statistics and trends of BP, and providing educational information. App developers should now aim to provide other components of self-management techniques to help individuals tackle hypertension.
\end{abstract}

Keywords: Smartphone apps; self-management; hypertension; blood pressure (BP); DASH diet

Received: 22 June 2021; Accepted: 14 October 2021; Published: 20 April 2022.

doi: $10.21037 /$ mhealth-21-25

View this article at: https://dx.doi.org/10.21037/mhealth-21-25

\section{Introduction}

Hypertension has been identified as the leading modifiable risk factor for cardiovascular diseases such as stroke heart disease and premature death. Intake of a high sodium diet, low potassium intake, high body mass index, alcohol consumption, physical inactivity, and unhealthy diet can lead to an increased prevalence of hypertension (1).

Hypertension or "silent killer" is one of the major causes

^ ORCID of Mahima Kaur: 0000-0001-7147-4084; Harpreet Kaur: 0000-0002-6354-6479; Ashish Joshi: 0000-0002-4492-8084. 
of premature deaths worldwide, affecting approximately 1.13 billion people. The prevalence of hypertension has proliferated globally during the past decades, specifically in low-and middle-income countries (2). Additionally, some of the Southeast Asian countries have also reported a significantly higher rate of uncontrolled hypertension (3). As with other low- and middle-income countries (LMICs), the prevalence of hypertension is high in India and is also a leading risk factor attributable to premature deaths, chronic diseases, and disability (4). Literature also reports that hypertension is attributed to $10.8 \%$ of all deaths in the country (5). The prevalence of hypertension in the Indian context is $30.7 \%$, which affects $25-30 \%$ of middle-aged individuals in urban settings and $15-20 \%$ in rural settings of the country, on the other hand, it is also reported that these individuals have low hypertension awareness, treatment, and control $(5,6)$.

The Eighth Joint National Committee (JNC 8) recommends pharmacologic treatment should be begun among adults younger than 60 years when blood pressure (BP) is $140 / 90 \mathrm{mmHg}$ or higher (7). In 2018, European guidelines retained the earlier definition of hypertension (i.e., $\mathrm{BP}>140 / 90 \mathrm{mmHg}$ ). As per the European hypertension guidelines, South Asians are at the highest risk and most vulnerable to high BP levels along with the growing risk of diabetes mellitus (8). The latest revised American guidelines lowered the threshold to define hypertension as blood pressure of $>130 / 90 \mathrm{mmHg}(9,10)$. The fourth edition of the Indian Guidelines on Hypertension (IGH-IV) came out in the year 2019. The guidelines incorporated the recent changes in the diagnosis and management of hypertension and the changes in the target BP by the American College of Cardiology/American Heart Association (ACC/AHA). As per the guidelines, the diagnosis of hypertension should be based on a clinic blood pressure reading of $>140 / 90$ (11). For people at risk or patients having hypertension, the guidelines recommend frequent monitoring of blood pressure and tracking of non-pharmacologic measures such as the following of DASH diet, restriction of tobacco intake and alcohol intake, and reduction of body weight if needed, medication adherence, practicing of yoga and meditation $(11,12)$. Attention needs to be given to developing methods for at-risk individuals and hypertensive patients to selfmanage hypertension to reduce the complications. Lack of understanding of the relation between blood pressure, symptoms, and healthy lifestyle practices can lead to negative consequences of antihypertensive treatment (13).

Mobile health (mHealth) is widely used for health services and patient education. mHealth apps have been "prescribed" as part of the care for chronic illnesses by the UK Department of Health (14). In recent years, smartphones have become an essential part of our daily routine. The number of mobile cellular subscriptions is continually increasing every year. In 2016, there have been over seven billion users worldwide. Globally, the figure of internet users has increased 7 times between 2000 and 2015 from $6.5 \%$ to $43 \%$ (15). Globally there are about 3.6 billion smartphone users at present, and there is about an $8 \%$ increase in the number of smartphone users per year. In the global market, Android and iOS are the two dominating operating systems among the population (16). India is fast on the route of digitization and is predicted to reach 829 million smartphone users by 2022 (17). Android is the dominating OS in India accounting for $95.23 \%$ of the mobile operating systems (18). In 2019 India also became the leading market in terms of app downloads (17). Additionally, the number of medical apps downloaded increased by $90 \%$ in India during 2020, owing to COVID-19 (19).

There is a rapid increase in the popularity of the use of mobile healthcare apps in the self-management of various chronic diseases such as hypertension. Numerous types of interventions like tracking patient data, providing tailored self-management, and interactive communication are used to facilitate in self-care of diseases through smartphones. Two functions (I) measuring blood pressure and (II) managing records are considered to be the main function in any hypertension management apps (20). A systematic review conducted on content analysis for Blood Pressure apps highlighted recording of BP, feedback limiting to displaying graphical records, and exporting the values for better physician-patient communication to be the most common functions in the app (21).

The prevalence of chronic diseases across the developed world and now, in the developing world, is becoming an increasing burden. Therefore, the Health authorities are seeking to lower the burden by using technology to support and encourage self-care of chronic illnesses (22). People living in remote areas and the underserved population can utilize various technologies to overcome geographical barriers to seek healthcare. mHealth technologies such as smartphone applications can provide support in achieving universal health coverage by enhancing availability and accessibility to various healthcare services (23).

Since individuals with non-communicable diseases such as hypertension are turning to smartphone apps technologies for assistance there is a need to study the 

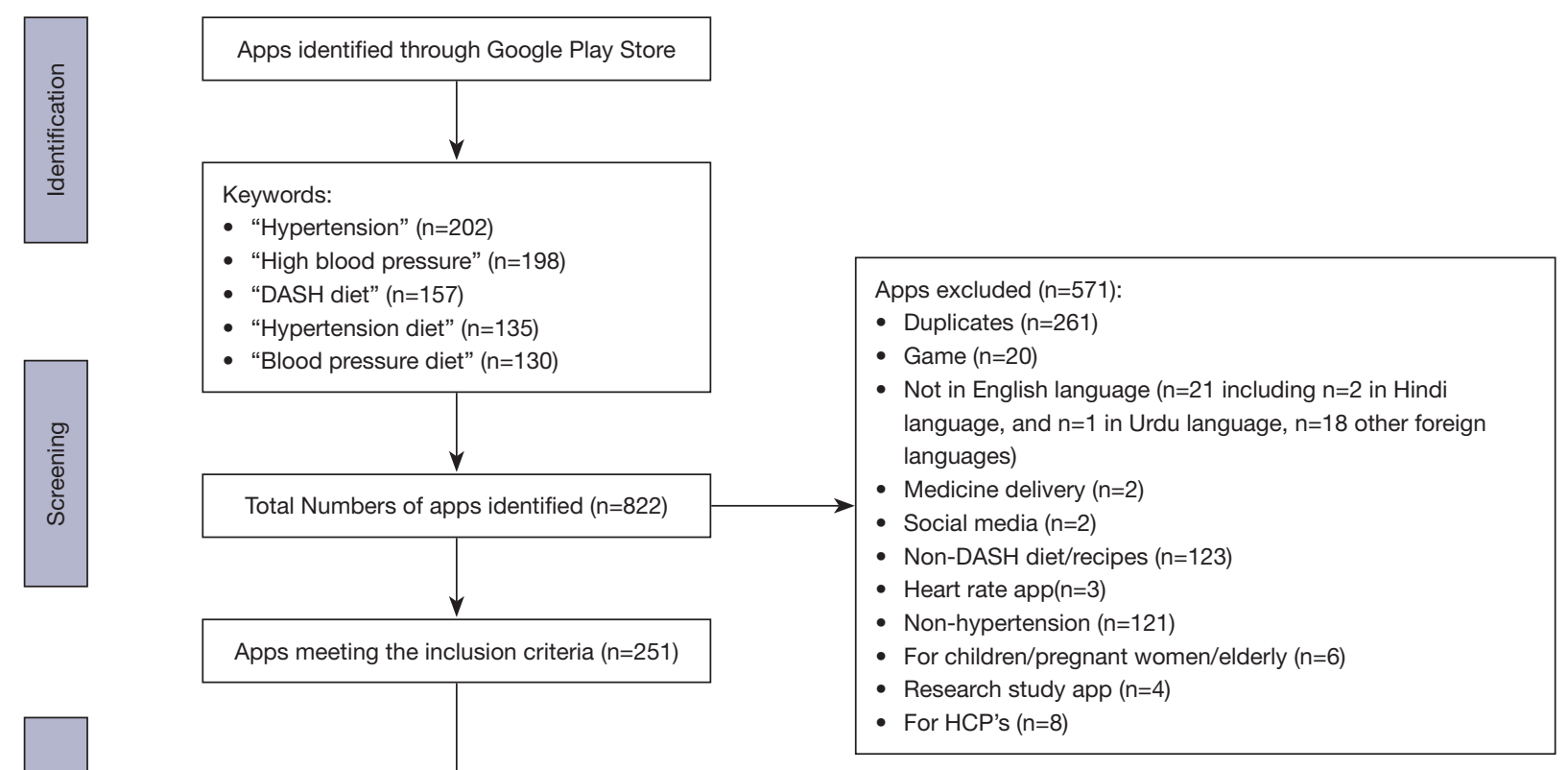

$$
\text { - "Blood pressure diet" }(n=130)
$$

Apps excluded $(n=41)$ :

- Broken Link $(n=6)$

- DASH diet/DASH recipes not relevant for Indian adults $(n=34)$

- Canadian hypertension guidelines $(n=1)$

Apps included for further analysis $(n=210)$

Figure 1 Flow diagram of the app-search process.

content and popularity of smartphone applications to avoid any negative effect on the condition (24). Assessing the functionalities of apps designed for consumers may help physicians recommend reliable and correct apps to promote self-management among patients.

The objective of our study was to review all the available apps related to hypertension/and high blood pressure and DASH Diet and investigate their main functional and analytical characteristics. Additionally, we aim to map how many apps meet the Self-Management Support (PRISMS) taxonomy. To the best of our knowledge, not many studies have analyzed all available apps; and considered functionality combinations in the Indian context.

\section{Methods}

\section{Study design}

This study is a features analysis and descriptive review of apps facilitating self-management of hypertension or high blood pressure available in the Google Play Store.

\section{Search strategy}

A search was conducted in February 2021 in India using the Google Play Store to identify currently available apps related to self-management of hypertension. Keywords entered into the Google Play Store search window included: 'Hypertension', 'High blood pressure', 'DASH diet', 'Hypertension diet', and 'Blood pressure diet'. The links of all the apps search were saved. If an app appeared in response to searches for more than one keyword by a platform, it was included only once. Further, the apps were screened for all exclusion and inclusion criteria. A total of 822 apps were screened based on the inclusion and exclusion criteria. Two hundred and ten $(\mathrm{n}=210)$ apps were included for further analysis. Variables of the included apps were extracted on $10^{\text {th }}$ March 2021 (Figure 1).

\section{Inclusion criteria}

An app was included based on the following criteria: (I) the description was written in English, and "Hypertension", 
"High blood pressure", "DASH diet", "Hypertension diet", "Blood pressure diet" was included in the keywords; (II) apps for adults (18 and above) and focused on hypertension or high blood pressure; (III) unique apps.

\section{Exclusion criteria}

An app was excluded based on the following criteria: (I) duplicates; (II) games; (III) not in English language; (IV) medicine delivery; (V) social media; (VI) non-DASH diet/ recipes; (VII) heart rate app; (VIII) non-hypertension; (IX) for children/pregnant women/elderly; (X) research study app; (XI) for HCP's; (XII) broken link; (XIII) DASH diet/DASH recipes not relevant for Indian adults; (XIV) Canadian hypertension guideline.

Country 'India' was by -default selected in the Google Play Store. The Google Play country determines what content we get in the play store. There is a variation in the apps, games, and content we see on the Google Play Store from country to country (25). Based on the country of search any app not utilizing JNC-8, ACC/AHA, or Indian hypertension guidelines were not included in the study. Additionally, based on the screenshot of the apps and the description apps focusing on the menu, diet, and recipes based on ingredients not commonly used in Indian settings were also excluded from the analysis giving the study the Indian context.

\section{Variable extraction}

The following variables were extracted from the search:

* Category: information was documented about the categories of apps. Few categories recorded were medical, health \& fitness, entertainment, books and reference, food and drink, and news \& magazine.

* The number of raters: information was documented about the number of ratings the included apps have received.

* Content rating/user group: information was noted about the target user group for whom the app was suitable to use.

* Overall app rating: information was collected on the overall user rating of every app included. The rating scale for apps on Google Play Store is from 0 (lowest rating) to 5 (highest rating). A high rating depicts higher user satisfaction rates.

* App features: information was gathered on various characteristic features provided by each app on the
Google Play Store which supported the mapping of the functional and analytical characteristics.

* The number of apps installed: data was documented about the number of times each included apps had been installed.

* App updates: information was extracted on the recently updated features and the year during which the apps were updated.

* App purchases \& interactive elements: information was collected on whether purchases could be made within the apps and interactive elements the apps offer.

* Advertisements: information was extracted on whether the apps had internal advertisements.

* Price: data was gathered regarding whether the app is free to download or paid for.

Information extracted from the description, general information, features, and news updates of the included app were used to map the functional and analytical characteristics.

\section{Functional characteristics of the app}

Functional characteristics were mapped and categorized based on the functionalities determined in previous studies done on hypertension apps $(24,26)$. Any additional function characteristics seen in the included apps were also mapped. Some of the functional characteristics included were: recording of blood pressure, knowledge building, diet management component (focusing on DASH diet), BP check reminders, dietician consultation, weight management (BMI tracker, BMI categorization, demonstration of exercises, fitness tracker), stress management, communication with HCPs and others, goal setting, and medication tracker.

\section{Analytical characteristics of the app}

Features of the app were extracted to map the analytical characteristics of the app. Analytical characteristics included in-app statistical analysis, in-app graphing of BP measurements, categorization of BP readings, feedback based on the BP measurements, export data for sharing with others and to the physicians, automatic data backup, the ability of the app to transfer BP data through devices via Bluetooth (27).

The characteristics were used to chart onto the Practical Reviews In Self-Management Support (PRISMS) taxonomy 
of self-management support. It is a tick list of 14 selfsupport strategies associated with self-management of individual's condition. The components resulted from a systematic meta-review of 969 trials and 30 qualitative studies of self-management support interventions $(28,29)$. The usefulness of the taxonomy has been validated by employing a self-management support intervention for cancer survivors (30). The detailed taxonomy list with adapted examples (31) is as follows.

\section{Knowledge about condition, risk factors ,management and prevention}

This component included apps disseminating authentic information regarding hypertension, its causes and risk factors, classification of BP, preventive and management measures.

\section{Information about available resources}

Apps mentioning links to American Heart Association, ICMR website and other associations including Indian or International for authentic dissemination of the educational resources were included in this component.

\section{Provision of specific clinical action plans}

Apps providing tailored feedback on what to do if BP is high and setting out actions to be taken when condition deteriorates were included in this component.

\section{Regular clinical review}

This component included app having the provision to record appointment details with the health care providers or aiding in booking appointment with the healthcare professionals.

\section{Monitoring of condition with feedback}

Apps providing the provision to record BP, classifying $\mathrm{BP}$, view in-app graphical trends and statistical analysis of $\mathrm{BP}$, and providing feedback based on the diagnosis were included in this component.

\section{Practical support with adherence (medication or behavioural)}

Apps providing medication reminder, BP check reminders, rewards for checking BP or recording it were included in this component.

\section{Provision of equipment}

Apps providing Bluetooth to directly transfer BP readings or connecting to $\mathrm{BP}$ machine for recording $\mathrm{BP}$ were included.

\section{Provision of easy access to advice or support when needed}

This component included app provided the provision for online healthcare professional consultation or communication via SMS/texts.

Training to communicate with healthcare professionals Apps providing the provision to transfer the health record to the physician for better communication were included in this component.

\section{Training for everyday activities}

Apps providing training to measure BP, oxygen levels or training on how to connect the app with the BP machine were included in this component.

\section{Training for practical self-management activities}

Apps providing logging reminder, recording personal health profile to put together for emergency situations, BP check reminders, ability to set goals were included in this component.

\section{Training for psychological strategies}

This included apps which demonstrated videos regarding breathing exercises to relieve stress/anxiety/tension to lower hypertension.

\section{Social support}

Apps having discussion forums to share stories on how they manage or prevent high blood pressure were considered having social support component.

\section{Lifestyle advice and support}

This included apps which provided DASH/low sodium diet guidance to lower BP, instructions on physical activity, relaxing breathing exercises to manage stress, along with tracking, reminder/alert services.

\section{Statistical analysis}

Descriptive statistics were used to summarize and evaluate the app features. Descriptive analysis for the continuous and categorical variables was performed. The mean, median, and range were identified for the continuous variables, whereas percentage distributions were found for the categorical 
Table 1 General characteristics and user interactive metrics of the included apps

\begin{tabular}{|c|c|}
\hline General characteristics & Statistics \\
\hline \multicolumn{2}{|l|}{ Price, n (\%) } \\
\hline Free & $199(95 \%)$ \\
\hline Paid & $11(5 \%)$ \\
\hline \multicolumn{2}{|l|}{ Advertisement, n (\%) } \\
\hline Yes & $153(73 \%)$ \\
\hline No & $57(27 \%)$ \\
\hline \multicolumn{2}{|l|}{ App updates year, n (\%) } \\
\hline 2011 & $2(1 \%)$ \\
\hline 2013 & $2(1 \%)$ \\
\hline 2014 & $5(2 \%)$ \\
\hline 2015 & $2(1 \%)$ \\
\hline 2016 & $8(4 \%)$ \\
\hline 2017 & $12(6 \%)$ \\
\hline 2018 & $19(9 \%)$ \\
\hline 2019 & $37(17 \%)$ \\
\hline 2020 & $83(39 \%)$ \\
\hline 2021 & $40(19 \%)$ \\
\hline \multicolumn{2}{|l|}{ In-app purchases, n (\%) } \\
\hline Yes & $37(18 \%)$ \\
\hline No & $173(82 \%)$ \\
\hline In-app purchases price, range & Rs 62 to Rs 9,300 \\
\hline Size in megabytes, mean (median) & $11.34(5.5)$ \\
\hline \multicolumn{2}{|l|}{ Content rating, n (\%) } \\
\hline $3+$ & $207(98.5 \%)$ \\
\hline $12+$ & $2(1 \%)$ \\
\hline $16+$ & $1(0.5 \%)$ \\
\hline $\begin{array}{l}\text { Rating for the app on a scale of } 5 \text {, } \\
\text { mean } \pm S D \text { (range) }\end{array}$ & $3.01 \pm 1.85$ ( 0 to 5$)$ \\
\hline \multicolumn{2}{|l|}{ Overall rating (on a scale of 5), $\mathrm{n}(\%)$} \\
\hline Less than 3.0 & $60(28 \%)$ \\
\hline 3.0 to 3.4 & $10(5 \%)$ \\
\hline 3.5 to 3.9 & $44(21 \%)$ \\
\hline 4.0 to 4.4 & $59(28 \%)$ \\
\hline More than or equal to 4.5 & $37(18 \%)$ \\
\hline
\end{tabular}

Table 1 (continued)
Table 1 (continued)

\begin{tabular}{lc}
\hline General characteristics & Statistics \\
\hline Apps users reviews, $\mathrm{n}(\%)$ & $170(81 \%)$ \\
Less than 500 & $7(3.4 \%)$ \\
500 to 999 & $33(15.6 \%)$ \\
Equal to or more than 1,000 & $19(9 \%)$ \\
Number of reviews mean \pm SD (range) $1,125 \pm 4,215(0$ to 47,273$)$ \\
Country of development of app, n (\%) \\
USA & $4(2 \%)$ \\
UK & $19(9 \%)$ \\
India & $38(18 \%)$ \\
Other & $130(62 \%)$ \\
Not mentioned & \\
\hline SD, standard deviation; USA, United States of America; UK, \\
United Kingdom.
\end{tabular}

variables. The obtained data were analyzed using Microsoft Excel 2016 and R version 4.0.4 (2021-02-15) software.

\section{Results}

\section{Summary of the search results}

A search of the Google Play Store yielded a total of 822 apps. The titles, descriptions, and features of these apps were screened for eligibility. A total of 210 unique apps were considered for further analysis.

\section{General characteristics}

General characteristics of all the apps are summarized in Table 1. Most apps ( $\mathrm{n}=199,95 \%)$ were free to download. Thirty-seven apps had in-app purchases and their price ranged from Rs 62 to Rs 9,300. In January and February 2021, 40 (19\%) apps were updated. More than half of the apps $(62 \%, \mathrm{n}=130)$ did not mention the country where the app was developed. About $41 \%$ of the apps belonged to the medical category and $41 \%$ of the apps were characterized in the health and fitness category (Figure 2).

\section{User interactive metrics}

According to the number of installs, only $28 \%$ of the app $(\mathrm{n}=60)$ had over $50 \mathrm{~K}$ downloads (Figure 3). Individual apps can be rated by the consumer as one, two three, four, or five stars. The average overall rating of the app 


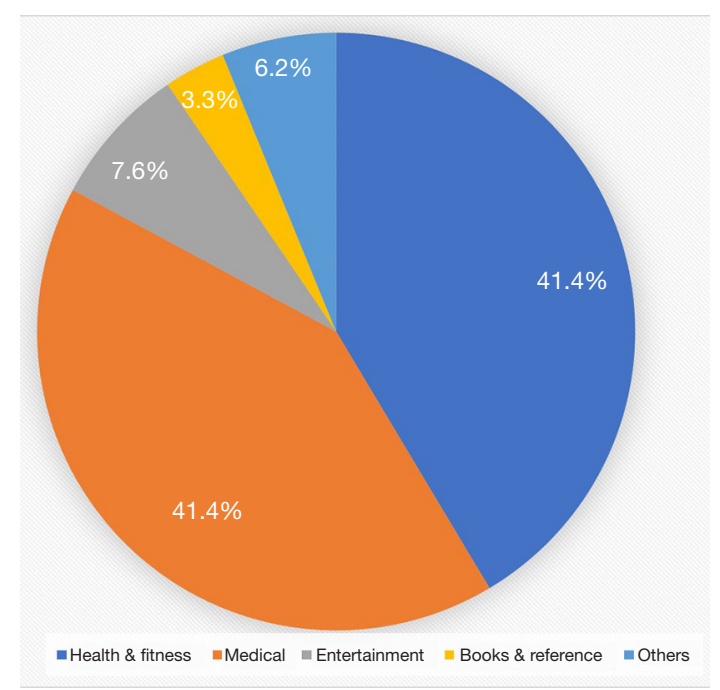

Figure 2 Percentage of apps per category (others include: tools, simulation, food and drink, social, news \& magazine, education, productivity).

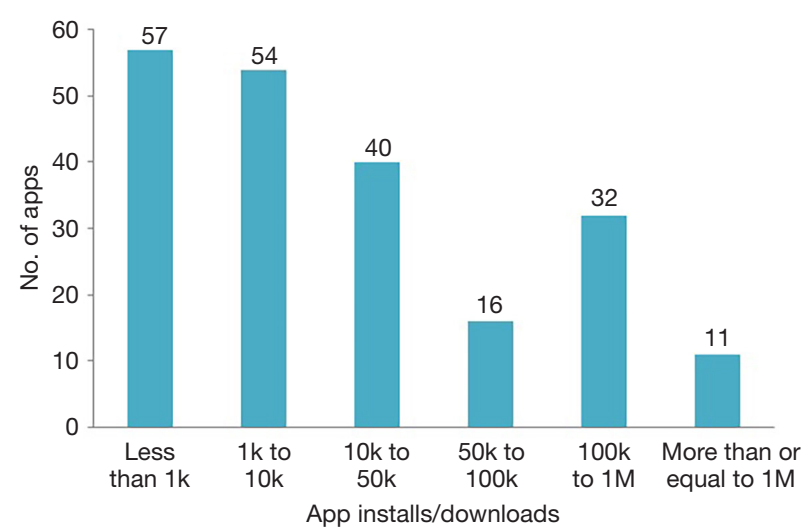

Figure 3 Number of apps based on installs/download.

on a scale of one to five, with five being the best, was recorded. Eighteen percent $(n=37)$ of the apps had an overall rating of 4.5 or above while, $28 \%(n=59)$ of the apps had an average overall rating of 4.0 to 4.4 (Table 1). Apps with an overall rating of 5 are described in Table 2. Figures 4,5 presents the distribution of ratings and number of downloads of the apps of various categories. Most of the apps related to hypertension were categorized under the 'Health and Fitness' $(n=87)$ or 'Medical' $(n=87)$ category. The median overall rating of the apps under the medical category was 4.0 and the mean was 3.4. The mean and median of installs under the medical category were
114,851 , and 5,000 respectively. There was one app under the medical category which had $1 \mathrm{M}$ installs. While mean and median of the overall rating of apps under the Health and Fitness category were 2.5 and 3.6 respectively. The mean and median of installs of apps under this category were 78,086 and 10,00 respectively which were lower than the medical category.

In total 16 apps belonged to the 'Entertainment Category'. The mean and median of the overall rating of apps were 4.2 and 4.0 respectively. On average the apps in the 'Entertainment category has 30,000 installs. Apps under the 'Heath and Fitness' category appear to have a large variability in overall rating as compared to the apps under the 'Medical' and 'Entertainment' category, even though the number of apps was similar in the 'Heath and Fitness' and 'Medical' category.

\section{Functional characteristics of the app}

All apps were classified according to their functionalities. The most common functionality seen across the apps was logging or recording the blood pressure measurements $(73 \%, n=154)$. One-third of the apps were recording other health parameters such as heart rate, blood sugar, cholesterol, blood count levels. Educational information was also common self-management functionality $(36 \%, n=75)$. Most apps gave information on the general information of hypertension, its risk factors, management of hypertension through diet (e.g., dietary approaches to stop hypertension). Details of the functional characteristics across the apps are described in Table 3.

Figure 6 depicts in detail the various tracking parameters available in the apps. Each of the apps had at least one tracking functional characteristic. Blood pressure tracking was most commonly available across the apps $(68 \%, \mathrm{n}=142)$. Heart rate/Pulse tracker was the second most common tracking functional characteristic $(36 \%, \mathrm{n}=75)$. A few apps focused on tracking medication $(\mathrm{n}=19)$, sodium intake $(\mathrm{n}=2)$, and calorie $(n=4)$. Additional important micronutrient: potassium was not being tracked in any of the apps.

\section{Analytical characteristics of the included app}

Table 4 enlists all the analytical characteristics. In-app graphing to analyze BP trends was reported in 64\% $(n=134)$ of the apps. Only 47\% ( $n=99)$ of the apps were categorizing the BP measurements according to the classification. 
Table 2 Top most popular apps for hypertension based on overall rating of 5

\begin{tabular}{|c|c|c|c|c|c|c|c|c|c|c|c|c|c|c|c|c|}
\hline Name of the app & $\begin{array}{l}\text { Educational } \\
\text { information }\end{array}$ & $\begin{array}{l}\text { In-apps graphing to } \\
\text { analyse BP trends }\end{array}$ & $\begin{array}{l}\text { In-app statistical } \\
\text { analysis }\end{array}$ & $\begin{array}{l}\text { Categorisation } \\
\text { of the BP } \\
\text { measurements }\end{array}$ & $\begin{array}{c}\mathrm{BP} \\
\text { reminder }\end{array}$ & $\begin{array}{l}\text { BP log/ } \\
\text { record }\end{array}$ & $\begin{array}{l}\text { BMI } \\
\text { tracker }\end{array}$ & $\begin{array}{l}\text { Blood Sugar } \\
\text { tracker }\end{array}$ & $\begin{array}{l}\mathrm{BP} \\
\text { tracker }\end{array}$ & $\begin{array}{l}\text { Pulse } \\
\text { tracker }\end{array}$ & $\begin{array}{c}\text { Diet } \\
\text { management }\end{array}$ & $\begin{array}{l}\text { Patient-physician } \\
\text { communication }\end{array}$ & $\begin{array}{l}\text { Exportation } \\
\text { statement }\end{array}$ & $\begin{array}{c}\text { Data } \\
\text { restoration }\end{array}$ & $\begin{array}{c}\text { Automatic } \\
\text { backup of the } \\
\text { measurements }\end{array}$ & Links \\
\hline Know Hypertension & $\times$ & & & $x$ & & & & & & & & & & & & $\begin{array}{l}\text { https://play.google.com/store/apps/ } \\
\text { details?id=appinventor.ai_rabiekore.KnowHypertension }\end{array}$ \\
\hline $\begin{array}{l}\text { ezeBP - Free Blood } \\
\text { Pressure Diary and } \\
\text { Analyzer }\end{array}$ & & $x$ & $x$ & $x$ & $x$ & $x$ & & & $x$ & $x$ & & $x$ & $x$ & $x$ & $x$ & $\begin{array}{l}\text { https://play.google.com/store/apps/details?id=com. } \\
\text { smashappz.ezebp }\end{array}$ \\
\hline Blood Pressure App & & $x$ & $x$ & $x$ & & $x$ & $x$ & $x$ & $x$ & $x$ & & & & $x$ & $x$ & $\begin{array}{l}\text { https://play.google.com/store/apps/details?id=com. } \\
\text { waterfullrainbow.bloodpressureanalyze }\end{array}$ \\
\hline $\begin{array}{l}\text { Blood Pressure } \\
\text { Recorder \& BP Diary } \\
2021\end{array}$ & & $x$ & & & & $x$ & $x$ & $x$ & $x$ & $x$ & $x$ & & & & $x$ & $\begin{array}{l}\text { https://play.google.com/store/apps/details?id=com. } \\
\text { rizapp.bloodpressureRecorder }\end{array}$ \\
\hline $\begin{array}{l}\text { Blood Pressure } \\
\text { Checker Reports }\end{array}$ & & $x$ & $x$ & $x$ & & $x$ & $x$ & & $x$ & $x$ & & & & & $x$ & $\begin{array}{l}\text { https://play.google.com/store/apps/details?id=com. } \\
\text { nixonappsstudio.bloodpressurechecker.reports }\end{array}$ \\
\hline $\begin{array}{l}\text { BP Checking App } \\
\text { Info Record }\end{array}$ & & $x$ & $x$ & $x$ & & $x$ & & & $x$ & $x$ & & & & & $x$ & $\begin{array}{l}\text { https://play.google.com/store/apps/details?id=com. } \\
\text { bpcheckingapp.bp.checking.app.info.record }\end{array}$ \\
\hline $\begin{array}{l}\text { Blood Pressure } \\
\text { Checker }\end{array}$ & & & & & & $\times$ & $x$ & $x$ & $x$ & $x$ & & & & & & $\begin{array}{l}\text { https://play.google.com/store/apps/details?id=com. } \\
\text { arjunneddyapps.bloodpressurecheckerinfo.blood. } \\
\text { pressure.checker.info }\end{array}$ \\
\hline
\end{tabular}

BP, blood pressure; BMI, body mass index.

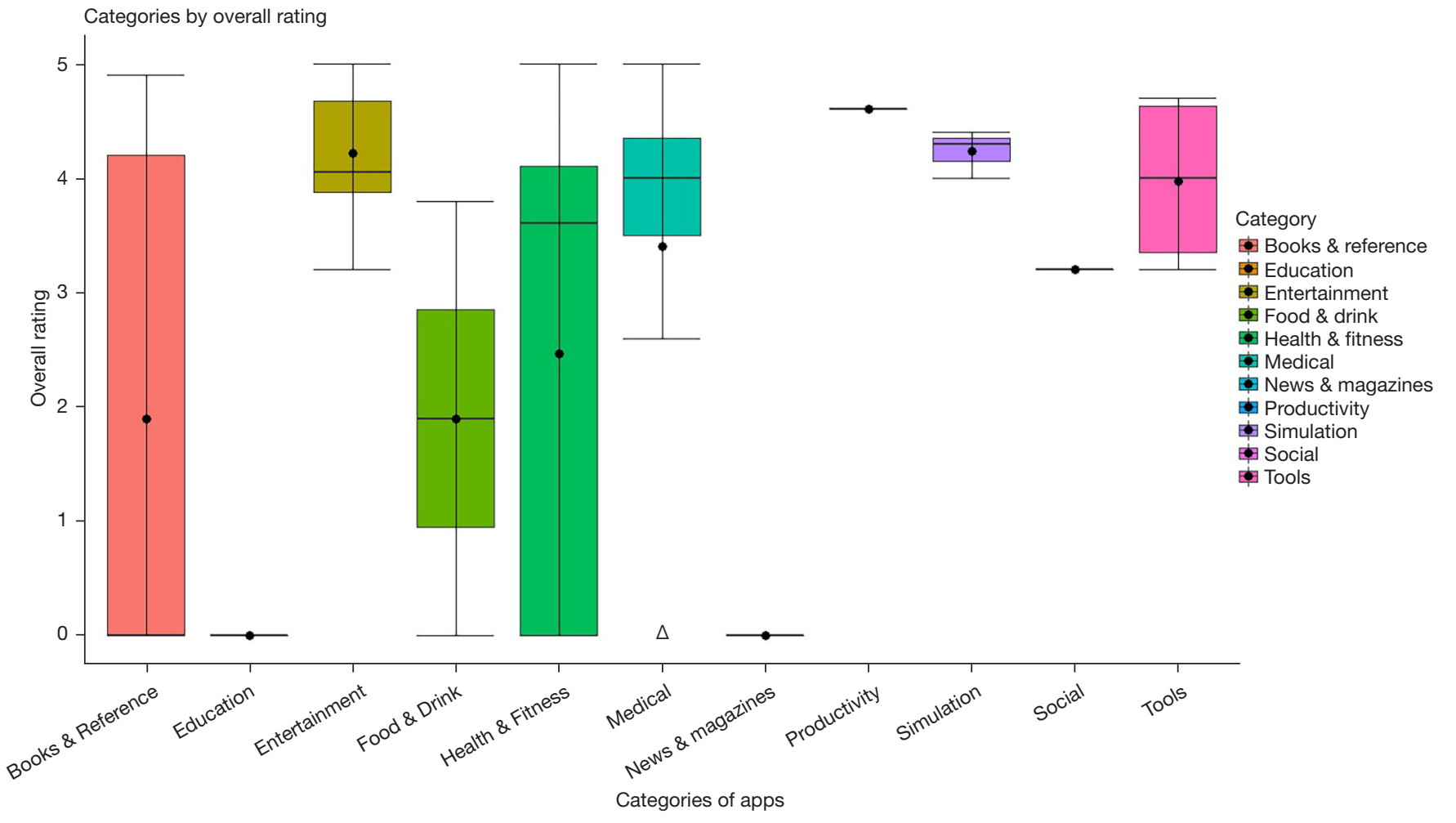

Figure 4 Box Plot of all the categories by the overall rating of the app. " $\Delta$ " represents outliers.
Categories by installs

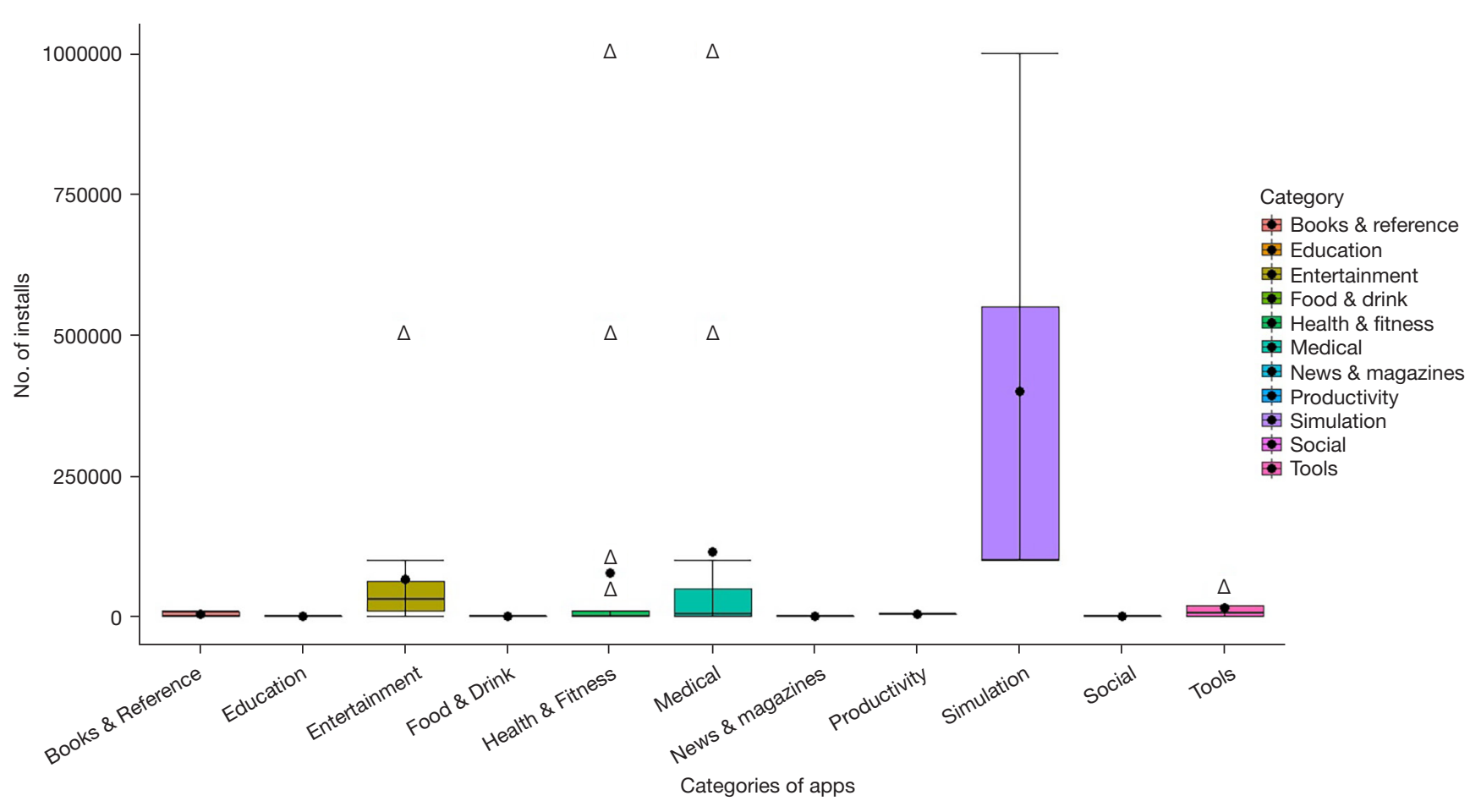

Figure 5 Box Plot of all the categories by the number of installs. " $\triangle$ ” represents outliers. 
Table 3 Functional characteristics of the app

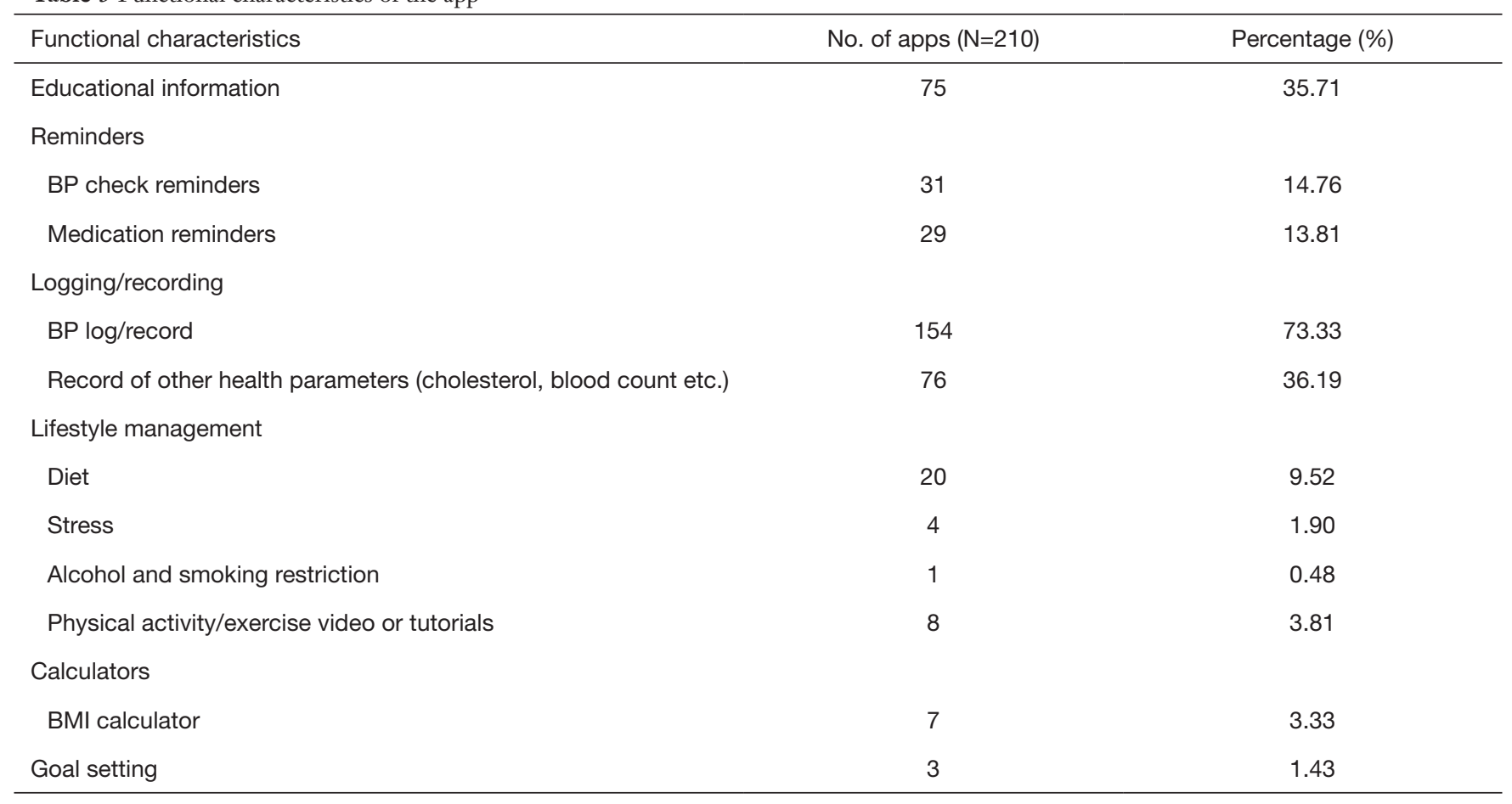

$\mathrm{BP}$, blood pressure; BMI, body mass index.

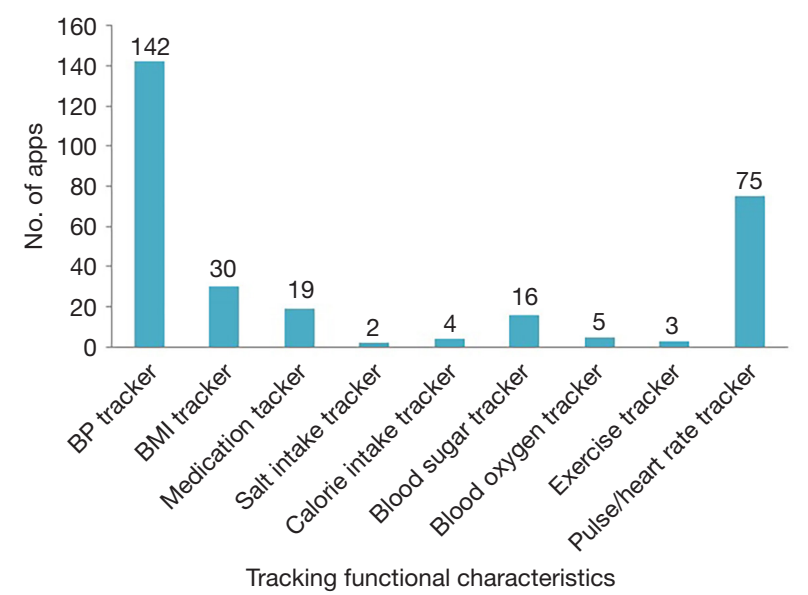

Figure 6 Tracking functional characteristics of the App. BP, blood pressure; BMI, body mass index.

Figure 7 depicts the total number of characteristics including both functional and analytical characteristics. We had identified 29 total characteristics among 210 apps. None of the apps had all 29 characteristics. About onetenth of the total apps included six characteristics. The Medical category apps had the highest number of average characteristics (Figure 8).

\section{Overall ratings of the app and the number of installs}

Figure 9 depicts a comparison between the overall ratings of the app and the number of installs. As the number of installs increased the overall ratings of the apps improved. Of the apps which had 100+ installs 23 apps had an overall rating of less than 3.0. All the apps which had $1 \mathrm{M}$ plus install had an overall rating of 3.5 and above. Apps with $1 \mathrm{M}$ installs are detailed in Table 5 .

\section{Components of the PRISMS taxonomy}

Out of the 14 self-management support components of the PRISMS taxonomy three components were not provided by any of the included apps. None of the apps had all the 14 PRISMS taxonomy components. More than half ( $\mathrm{n}=156,74 \%$ ) of the included apps included the 'monitoring condition with feedback' item. Only one-fourth of the app had a Lifestyle advice and support component (Table 6).

\section{Discussion}

This study highlights the review of apps on hypertension and DASH diet apps offered on the Google Play Store. The 
Table 4 Analytical characteristics of the apps

\begin{tabular}{lcc}
\hline App analytical characteristics & Number of app (N) & Percentage (\%) \\
\hline In-apps graphing to analyze BP trends & 134 & 63.81 \\
Text-based feedback on BP entries & 1 & 0.48 \\
Classification of the BP measurements & 99 & 47.14 \\
Transformation of the phone to a medical device to measure BP & 1 & 0.48 \\
Transmission of BP data through devices via Bluetooth & 12 & 5.71 \\
In-app statistical analysis & 94 & 44.76 \\
Exportation statements & 71 & 33.81 \\
Data restoration & 29 & 13.81 \\
Automatic backup of the measurements & 69 & 32.86 \\
\hline
\end{tabular}

$\mathrm{BP}$, blood pressure.

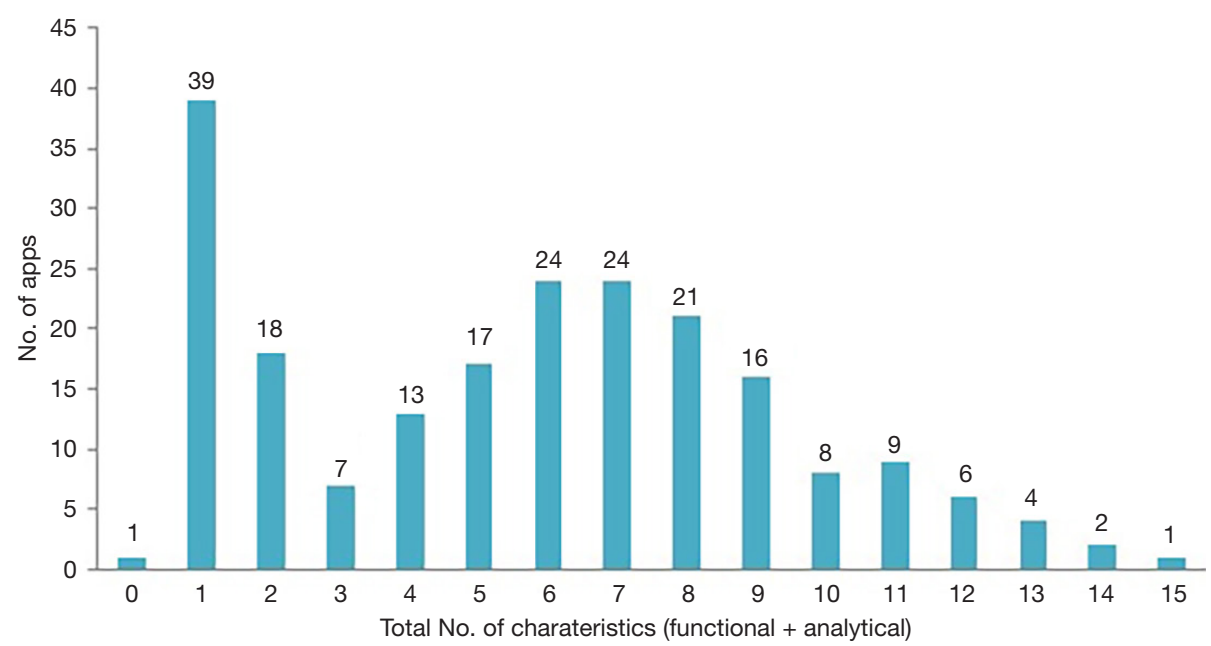

Figure 7 Total number of characteristics (functional + analytical).

review displays an abundance of android apps associated with self-management of hypertension. In total 210 unique apps were considered for analysis. Eighteen percent of the apps had an overall rating of 4.5 or above. About $41 \%$ of the apps belonged to the medical category and $41 \%$ of the apps were characterized in the health and fitness category.

Approximately one-sixth of the apps in our study had a BP and/or medication reminder function. Reminder features can perform a vital role in facilitating adherence and self-reliance regarding the condition. Goal-setting is a key strategy to enhance self-efficacy and significantly change behavior. Patients use mHealth apps to meet various goals to self-manage their conditions. If the functional features of mHealth apps fail to meet patient needs, it results in reduced patient motivation for using these apps (32). In our study; only three apps had the feature of goal setting to help individuals self-manage the condition. Blood pressure tracking was most commonly available across the apps $(68 \%)$. Heart rate/Pulse tracker was the second most common tracking functional characteristic (36\%). Most apps with self-monitoring features focused on BP tracking activity but other important features such as diet (such as salt intake, potassium intake, calorie, and carbohydrates intake), physical activity, sleep, and mental health/stress management were neglected. Not much has changed in the features available on apps to self-manage hypertension. 


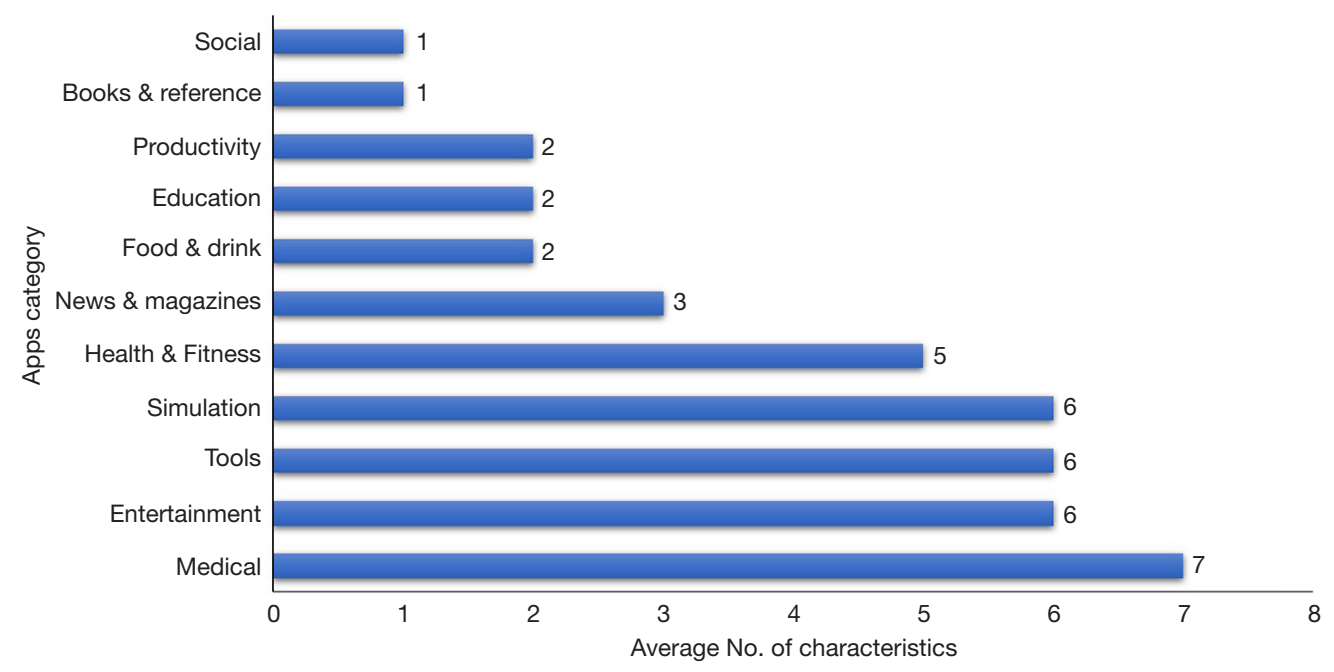

Figure 8 Average number of characteristics per category.

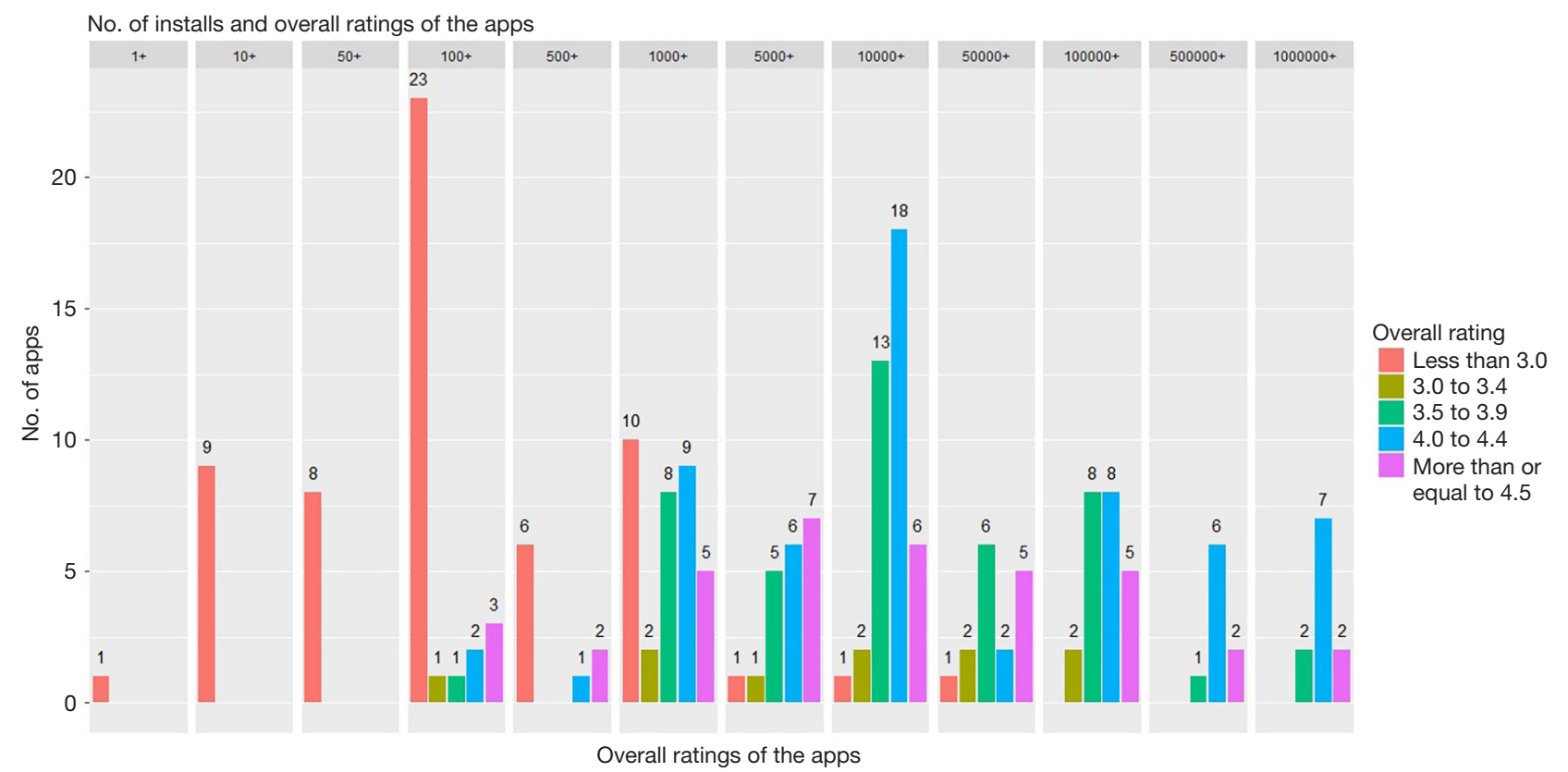

Figure 9 Overall ratings of the app and the number of installs.

Our results are similar to the study performed by Kumar et al. [2015], they concluded that $72 \%$ contained a tracking function, $22 \%$ had tools to enhance medication adherence and $8 \%$ had information on the DASH diet (24).

Of the total apps included in the study, only $64 \%$ of the apps provided the users a graphical representation of their BP measurements and $45 \%$ of the apps provided statistical analysis. Less than $50 \%$ of the apps were categorizing the $\mathrm{BP}$ measurements according to the Hypertension classification. Only around 5\% ( $\mathrm{n}=12)$ of the included apps were capable to directly transfer the BP measurements through the device via Bluetooth. Only one app out of the 210 apps provided feedback based on the BP measurements of the individual for further improvement in the condition. About one-third of the apps could directly export the recorded BP measurements to a physician. The transfer of the reports could thereby greatly improve patient-physician communication. 
Table 5 Top most popular apps for hypertension-based installs $\left(1 \mathrm{M}^{+}\right)$

\begin{tabular}{|c|c|c|c|c|c|c|c|c|c|c|c|c|c|c|c|c|c|c|c|c|c|}
\hline $\begin{array}{l}\text { Name of the } \\
\text { app }\end{array}$ & $\begin{array}{l}\text { Educational } \\
\text { information }\end{array}$ & $\begin{array}{c}\text { In-apps } \\
\text { graphing to } \\
\text { analyse BP } \\
\text { trends }\end{array}$ & $\begin{array}{l}\text { In-app } \\
\text { statistical } \\
\text { analysis }\end{array}$ & $\begin{array}{l}\text { Categorisation } \\
\text { of the BP } \\
\text { measurements }\end{array}$ & $\begin{array}{l}\mathrm{BP} \\
\text { reminder }\end{array}$ & $\begin{array}{l}\text { Medication } \\
\text { reminders }\end{array}$ & $\begin{array}{l}\text { Medication } \\
\text { tracker }\end{array}$ & $\begin{array}{l}\text { BP log/ } \\
\text { record }\end{array}$ & $\begin{array}{l}\text { BMI } \\
\text { tracker }\end{array}$ & $\begin{array}{l}\text { Blood } \\
\text { sugar } \\
\text { tracker }\end{array}$ & $\begin{array}{l}\mathrm{BP} \\
\text { tracker } \mathrm{t}\end{array}$ & $\begin{array}{l}\text { Pulse } \\
\text { tracker }\end{array}$ & $\begin{array}{l}\text { Oxygen } \\
\text { tracker }\end{array}$ & $\begin{array}{l}\text { Record of other } \\
\text { parameters } \\
\text { (weight, pulse) }\end{array}$ & $\begin{array}{c}\text { Goal } \\
\text { setting }\end{array}$ & $\begin{array}{l}\text { Patient-physician } \\
\text { communication }\end{array}$ & $\begin{array}{l}\text { Exportation } \\
\text { statement }\end{array}$ & $\begin{array}{l}\text { Data } \\
\text { restoration }\end{array}$ & $\begin{array}{c}\text { Transmission of } \\
\text { BP data through } \\
\text { devices via } \\
\text { Bluetooth } \\
\end{array}$ & $\begin{array}{l}\text { Automatic } \\
\text { backup of the } \\
\text { measurements }\end{array}$ & Links \\
\hline Blood Pressure & & $x$ & $x$ & $x$ & $x$ & & & $x$ & $x$ & & $x$ & $x$ & & & & & $x$ & & & $x$ & $\begin{array}{l}\text { https:///play.google.com/store/ } \\
\text { apps/details?id=com.jackywill. } \\
\text { bloodpressurerecord }\end{array}$ \\
\hline $\begin{array}{l}\text { Blood Pressure } \\
\text { Diary }\end{array}$ & & $\times$ & $x$ & $x$ & $x$ & & $x$ & $x$ & & & $x$ & $x$ & & & & & & & & $x$ & $\begin{array}{l}\text { https://play.google.com/ } \\
\text { store/apps/details?id=com. } \\
\text { interactivespecializedsoftware. } \\
\text { bloodpressurediary }\end{array}$ \\
\hline $\begin{array}{l}\text { Blood Pressure } \\
\text { Log - My Diary }\end{array}$ & & $x$ & $x$ & $x$ & & & & $x$ & $x$ & $x$ & $x$ & & $x$ & & & $x$ & $x$ & & & $x$ & $\begin{array}{l}\text { https:///play.google.com/store/apps, } \\
\text { details?id=com.zlamanit.blood. } \\
\text { pressure }\end{array}$ \\
\hline Blood Pressure & $x$ & & & & & & & & & & & & & & & & & & & & $\begin{array}{l}\text { https://play.google.com/store/apps } \\
\text { details?id=com.szyk.myheart }\end{array}$ \\
\hline $\begin{array}{l}\text { Blood Pressure } \\
\text { History }\end{array}$ & $x$ & $x$ & $x$ & $x$ & & & & $x$ & & & $x$ & $x$ & & & & & & & & $x$ & $\begin{array}{l}\text { https:///play.google.com/store/apps, } \\
\text { details?id=com.waterfullrainbow. } \\
\text { bloodpressurehistory }\end{array}$ \\
\hline $\begin{array}{l}\text { Blood Pressure } \\
\text { (BP) Watch }\end{array}$ & & $x$ & $x$ & $x$ & $x$ & & & $x$ & $x$ & & $x$ & $x$ & & $x$ & & & & & & $x$ & $\begin{array}{l}\text { https:///play.google.com/store/apps, } \\
\text { details?id=com.boxeelab.healthlete } \\
\text { bpwatch }\end{array}$ \\
\hline $\begin{array}{l}\text { My Blood } \\
\text { Pressure }\end{array}$ & $x$ & & & & & & & & & & & & & & & & & & & & $\begin{array}{l}\text { https://play.google.com/store/apps, } \\
\text { details?id=com.fakeconversations }\end{array}$ \\
\hline $\begin{array}{l}\text { Cardio Journal - } \\
\text { Blood Pressure } \\
\text { Log }\end{array}$ & $x$ & $x$ & $x$ & $x$ & $x$ & $x$ & $x$ & $x$ & & & $x$ & & & & & $x$ & $x$ & $x$ & & $x$ & $\begin{array}{l}\text { https://play.google.com/store/ } \\
\text { apps/details?id=com.mdhelper. } \\
\text { cardiojournal }\end{array}$ \\
\hline $\begin{array}{l}\text { Blood Pressure } \\
\text { Diary }\end{array}$ & & & $x$ & $x$ & & $x$ & & $x$ & & & $x$ & $x$ & $x$ & $x$ & & & $x$ & & & $x$ & $\begin{array}{l}\text { https://play.google.com/ } \\
\text { store/apps/details?id=com. } \\
\text { interactivespecializedsoftware. } \\
\text { bloodpressurediary }\end{array}$ \\
\hline $\begin{array}{l}\text { OMRON } \\
\text { connect }\end{array}$ & & $x$ & $x$ & $\times$ & & & & $x$ & & & $x$ & & & $x$ & & & & & & $x$ & $\begin{array}{l}\text { https:///play.google.com/store/apps, } \\
\text { details?id=jp.co.omron.healthcare. } \\
\text { omron_connect }\end{array}$ \\
\hline
\end{tabular}

BP, blood pressure; BMI, body mass index. 
Table 6 No. of apps meeting the PRISMS components

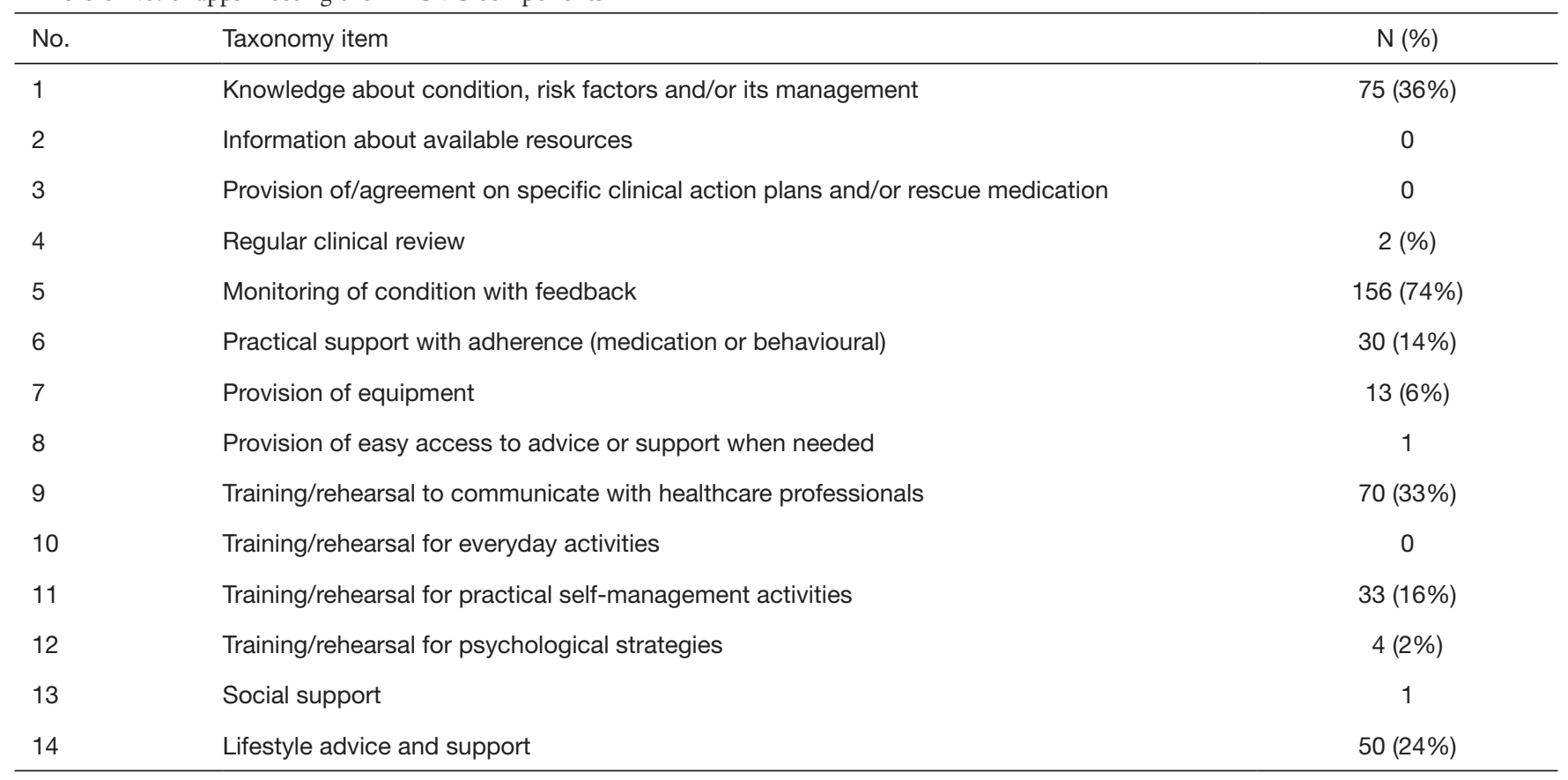

Another study conducted on the content analysis of hypertension apps available on the Apple Store and Google Play Store in 2018 in the United Kingdom found the most common self-management educational information about hypertension $(59.1 \%)$ to be the most common selfmanagement. functionality which was commonly seen in our study as well. Self-monitoring $(53.2 \%)$ was seen to be the second most common functionality to be present where the majority of these apps ( $n=94)$ aided in BP tracking. Another common functionality was the provision of automatic feedback (28\%), and BP measurements reminder (21\%). Similar to be our study, few apps included the component of stress management $(2.7 \%)$, BP goal setting $(5.4 \%)$ and had a provision for tracking medication compliance, potassium intake, or sodium intake (26).

In our review out of the 14 self-management support components of the PRISMS, taxonomy three components were not provided by any of the included apps. None of the apps had all the 14 PRISMS taxonomy components. Our findings are similar to a study conducted in 2018 for hypertension apps available in the United Kingdom. The apps which were reviewed by the authors rarely incorporated the components of self-management support (31).

In our review, 34 apps were not excluded in the analysis because they were not appropriate for the Indian population. Only 20 of the included apps focused on the dietary component to manage hypertension by incorporating Indian-based diets. Dietary modifications are regarded as a cost-effective strategy with a high potential to prevent hypertension (33). The availability of widespread technology can motivate healthy eating. Nevertheless, such technological applications usually adopt a "one-sizefits-all" approach. These approaches are usually biased towards specific cultures, ethnic groups, or populations (34). Empirical studies suggest that diet and health promotion messages, tailored according to culture, ethnicity, and language are perceived as relevant and likely to address the needs of individuals and encourage them to engage in health-promoting behaviors. Besides tailored culturally appropriate diets can aid in reducing the burden of preventable diseases as they can be easily incorporated into the daily diet instead of a one-size-fits-all approach $(35,36)$. Personalized nutrition advice and messaging should include varied suggestions for meals and recipes according to what a person eats in a daily diet and foods that her affordable and easily accessible in addition to information about recommended amounts of nutrients or nutrients that should be avoided (37). It would be important to study whether the apps aimed at improving the blood pressure levels through diet delivers a tailored cultural messaging or utilizes a sizefits-all approach. More emphasis is needed to develop apps utilizing tailored, cultural, and behavioral approaches that 
will best encourage and promote sustained dietary changes in individual and different cultural and regional groups.

In this review, two apps in the Hindi language and one app in the Urdu language were focusing on selfmanagement of hypertension but they were excluded from the study based on non-English language exclusion criteria. None of the apps was present in other languages frequently used in India such as Punjabi, Marathi, Tamilian, etc. This states that there is a paucity of apps tailored as per the language needs of the Indian population to address the high prevalence of hypertension. As per the report by KPMG in India and Google in April 2017, by 2021 Indian language internet users are expected to account for nearly $75 \%$ of India's internet users. By 2021, Hindi internet user along with few other Indian languages is likely to outstand English user base. Besides, in the next 5 years, nine out of every 10 new internet users are expected to be users who use the Indian language (38). To address the language barrier, increase the reliability of the content and for higher visibility of the app where English is not the main language, app developers should try to incorporate bilingual or multilingual app content.

One of the vital recommendations to the app developer is that while curating the content for the app targeting any health condition, they should involve a medical professional. The involvement of medical professionals in developing the app will enhance the quality, accountability, accuracy, and transparency of the content. Besides, it will protect the users from getting exposed to the content, therapies, or commercial products which are scientifically not proven and can be potentially harmful. Nonetheless, there is a need to regulate and investigate the medical conditions apps by the medical and public healthcare organizations for the safety of the potential app users (39). To ensure the reliability and integrity of health information, medical experts and healthcare organizations can review and certify health apps, similar to existing Web page certification, such as the Health on the Net Foundation Code of Conduct (40). Nonevidence-based health and lifestyle apps should be carefully considered as they can lead to exposure to harmful content. Therefore, information on usability and effectiveness is crucial for potential app consumers. Additionally, data security and privacy issues are not often addressed in health apps. With the increase in the advancement of technology, importance should be given to secure patients' health data. App developers should guarantee the security and privacy of the app used in tracking and recording health data $(41,42)$.
Potential users primarily rely on attributes such as the name of the app, its user ratings, ranking, and reviews. This information plays an important role in the decision process of choosing an app to download. Additionally, apps with higher user ratings and ranks have high visibility and installation $(40,43)$. User ratings and frequency of app download are a measure of acceptability and popularity of the mobile app, indicating a favorable user experience (44), however, limited literature is available for evaluating the role of user ratings and quality of apps. Studies have also reported a bidirectional and contradictory relationship in this context, reporting higher user ratings implying higher app adherence and also a poor correlation between user ratings and app quality $(45,46)$. This context suggests an urgent need to expand the literature on the correlation between app ratings and quality of $m$-health apps.

Despite an extensive search of the apps, there are few limitations noted. Firstly, this cross-sectional study does not address changing trends and updates of apps. The search strategy and the analyses might lead to different results rapid changes in the Google Play Store market. Secondly, we did not take into consideration apps available in languages other than English. Thirdly, apps extracted were only from the Google Play Store, and apps from other operating systems such as $\mathrm{iOS}$ were not taken into consideration. The inclusion of only android-based apps limits the comprehensiveness of the study but including apps from these additional app stores was beyond the scope of this preliminary research. Besides, in the year 2020, Android held a share of $95.23 \%$ of the mobile operating system market followed by Apple's iOS, with a market share of $3.2 \%$ in India (18). Fourthly, to assess the features of the included apps we only reviewed the short description, general information, features, new updates, and the screenshot of the app provided by the app developer. None of the included apps was downloaded to evaluate the usability and effectiveness of apps from the perspective of healthcare professionals and hypertensive or at-risk patients. Since, it is a preliminary study to assess the features and the gaps in apps for hypertension, screenshots and the description can solve the purpose. As per the preview assets and content guidelines of google, app developers should add screenshots and short descriptions for their apps. Screenshots must focus on the main functions and the content and demonstrate the actual in-app experience to the potential users. The screenshots aids in conveying capabilities for better decisionmaking. In addition, the short description should highlight any characteristics that make the app unique and written in a way that the potential app users can quickly understand the 
core purpose of the app (47).

We intend to address some of the mentioned limitations by exploring hypertension apps on iTunes, along with conducting a follow-up study to assess the effectiveness and usability of the apps and their educational content by using them for few months.

This study involved an extensive search rather than limiting it to only the most popular apps and highly rated apps. A thorough analysis of the features can help app developers to understand the missing functionalities. The search saw numerous apps which were not related to the keywords. This identifies that there is a need to improve the designing of the app-store platforms, along with their filter and feedback capacities to reduce the information overload.

\section{Conclusions}

This study utilizes information available on the app's page which is what consumers would normally see at first before installing an app. The review demonstrated an overload of hypertension apps on the Google Play Store. There is a large availability and overload of apps for hypertensive patients which can cause difficulty in determine, identify and select the appropriate app to self-manage the disease. Lack of explicit criteria poses a difficulty in determining which app to choose and make an informed selection. Having all the criteria of self-care management in a single app will be beneficial to individuals dealing with hypertension as many do not want to download numerous health and lifestyle apps on their smartphones. It is necessary to develop a holistic self-management app that can provide a broad spectrum of intervention components to support individuals with hypertension. Also, there is a need to develop diseasespecific tailored evaluation tools to aid in finding the appropriate app among the myriad of available health and lifestyle apps. The efficacy, effectiveness, and usability of the app need to be evaluated by both the healthcare providers and the potential users to guide in the selection of the most appropriate app.

\section{Acknowledgments}

Funding: None.

\section{Footnote}

Data Sharing Statement: Available at https://mhealth. amegroups.com/article/view/10.21037/mhealth-21-25/dss
Peer Review File: Available at https://mhealth.amegroups. com/article/view/10.21037/mhealth-21-25/prf

Conflicts of Interest: All authors have completed the ICMJE uniform disclosure form (available at https://mhealth. amegroups.com/article/view/10.21037/mhealth-21-25/ coif). Ashish Joshi serves as an unpaid editorial board member of mHealth from December 2019 to November 2021. The other authors have no conflicts of interest to declare.

Ethical Statement: The authors are accountable for all aspects of the work in ensuring that questions related to the accuracy or integrity of any part of the work are appropriately investigated and resolved.

Open Access Statement: This is an Open Access article distributed in accordance with the Creative Commons Attribution-NonCommercial-NoDerivs 4.0 International License (CC BY-NC-ND 4.0), which permits the noncommercial replication and distribution of the article with the strict proviso that no changes or edits are made and the original work is properly cited (including links to both the formal publication through the relevant DOI and the license). See: https://creativecommons.org/licenses/by-nc-nd/4.0/.

\section{References}

1. Mills KT, Stefanescu A, He J. The global epidemiology of hypertension. Nat Rev Nephrol 2020;16:223-37.

2. World Health Organization. Hypertension 2021. Available online: https://www.who.int/news-room/fact-sheets/detail/ hypertension

3. Kow CS, Hasan SS, Wong PS, et al. Concordance of recommendations across clinical practice guidelines for the management of hypertension in Southeast Asia with internationally reputable sources. BMC Cardiovasc Disord 2021;21:354.

4. Rauniyar SK, Rahman MM, Rahman MS, et al. Inequalities and risk factors analysis in prevalence and management of hypertension in India and Nepal: a national and subnational study. BMC Public Health 2020;20:1341.

5. Gupta R, Yusuf S. Towards better hypertension management in India. Indian J Med Res 2014;139:657-60.

6. Gupta R, Gupta N. Hypertension epidemiology in the 21st century India. J Prev Cardiol 2013;2:350-5.

7. James PA, Oparil S, Carter BL, et al. 2014 evidence-based 
guideline for the management of high blood pressure in adults: report from the panel members appointed to the Eighth Joint National Committee (JNC 8). JAMA 2014;311:507-20.

8. Williams B, Mancia G, Spiering W, et al. 2018 ESC/ESH Guidelines for the management of arterial hypertension. Eur Heart J 2018;39:3021-104.

9. Whelton PK, Carey RM, Aronow WS, et al. 2017 ACC/ AHA/AAPA/ABC/ACPM/AGS/APhA/ASH/ASPC/ NMA/PCNA Guideline for the Prevention, Detection, Evaluation, and Management of High Blood Pressure in Adults: Executive Summary: A Report of the American College of Cardiology/American Heart Association Task Force on Clinical Practice Guidelines. Hypertension 2018;71:1269-324.

10. Swedberg K, Komajda M, Böhm M, et al. Ivabradine and outcomes in chronic heart failure (SHIFT): a randomised placebo-controlled study. Lancet 2010;376:875-85.

11. Shah SN, Munjal YP, Kamath SA, et al. Indian guidelines on hypertension-IV (2019). J Hum Hypertens 2020;34:745-58.

12. Ministry of Health \& Family Welfare Government of India. Standard Treatment Guidelines Hypertension: Screening, Diagnosis, Assessment, and Management of Primary Hypertension in Adults in India. India 2016. Available online: https://nhm.gov.in/images/pdf/ guidelines/nrhm-guidelines/stg/Hypertension_full.pdf

13. Hallberg I, Ranerup A, Kjellgren K. Supporting the selfmanagement of hypertension: Patients' experiences of using a mobile phone-based system. J Hum Hypertens 2016;30:141-6.

14. Sobnath DD, Philip N, Kayyali R, et al. Features of a Mobile Support App for Patients With Chronic Obstructive Pulmonary Disease: Literature Review and Current Applications. JMIR Mhealth Uhealth 2017;5:e17.

15. Parasuraman S, Sam AT, Yee SWK, et al. Smartphone usage and increased risk of mobile phone addiction: A concurrent study. Int J Pharm Investig 2017;7:125-31.

16. Chmielarz W. Study of smartphones usage from the customer's point of view. Procedia Comput Sci 2015;65:1085-94.

17. Association E. Contribution of Smartphones to digital governance in India. Available online: https://icea. org.in/wp-content/uploads/2020/07/Contributionof-Smartphones-to-Digital-Governance-inIndia-09072020.pdf

18. Department SR. Market share of mobile operating systems in India from 2012 to 2020. India 2021. Available online: https://www.statista.com/statistics/262157/market-shareheld-by-mobile-operating-systems-in-india

19. Stewart C. Growth in the number of medical apps downloaded during the COVID-19 pandemic by country in 2020*: Statista; 2020 [cited 2021 23rd August]. Available online: https://www.statista.com/statistics/1181413/ medical-app-downloads-growth-during-covid-pandemicby-country/

20. Kang H, Park HA. A Mobile App for Hypertension Management Based on Clinical Practice Guidelines: Development and Deployment. JMIR Mhealth Uhealth 2016;4:e12.

21. Jamaladin H, van de Belt TH, Luijpers LC, et al. Mobile Apps for Blood Pressure Monitoring: Systematic Search in App Stores and Content Analysis. JMIR Mhealth Uhealth 2018;6:e187.

22. Lewis J, Ray P, Liaw ST. Recent Worldwide Developments in eHealth and mHealth to more Effectively Manage Cancer and other Chronic Diseases - A Systematic Review. Yearb Med Inform 2016;(1):93-108.

23. Li R, Liang N, Bu F, et al. The Effectiveness of SelfManagement of Hypertension in Adults Using Mobile Health: Systematic Review and Meta-Analysis. JMIR Mhealth Uhealth 2020;8:e17776.

24. Kumar N, Khunger M, Gupta A, et al. A content analysis of smartphone-based applications for hypertension management. J Am Soc Hypertens 2015;9:130-6.

25. Google. How to change your Google Play country 2021. Available online: https://support.google.com/ googleplay/answer/7431675?hl=en\&co=GENIE. Platform\%3DAndroid

26. Alessa T, Hawley MS, Hock ES, et al. Smartphone Apps to Support Self-Management of Hypertension: Review and Content Analysis. JMIR Mhealth Uhealth 2019;7:e13645.

27. Leong AY, Makowsky MJ. Quality of Blood Pressure Tracking Apps for the iPhone: Content Analysis and Evaluation of Adherence With Home Blood Pressure Measurement Best Practices. JMIR Mhealth Uhealth 2019;7:e10809.

28. Pearce G, Parke HL, Pinnock H, et al. The PRISMS taxonomy of self-management support: derivation of a novel taxonomy and initial testing of its utility. J Health Serv Res Policy 2016;21:73-82.

29. Taylor SJC, Pinnock H, Epiphaniou E, et al. A rapid synthesis of the evidence on interventions supporting self-management for people with long-term conditions: PRISMS - Practical systematic Review of SelfManagement Support for long-term conditions. 
Southampton (UK): NIHR Journals Library, 2014.

30. Bourne C, Pearce G, Turner A, et al. Applying a novel taxonomy of self-management support components to the self-management support cancer HOPE manual. Nottingham, UK: Midlands Health Psychology Network (MHPN), 2014.

31. Hui CY, Creamer E, Pinnock H, et al. Apps to Support Self-Management for People With Hypertension: Content Analysis. JMIR Mhealth Uhealth 2019;7:e13257.

32. Duan H, Wang Z, Ji Y, et al. Using Goal-Directed Design to Create a Mobile Health App to Improve Patient Compliance With Hypertension Self-Management: Development and Deployment. JMIR Mhealth Uhealth 2020;8:e14466.

33. Bazzano LA, Green T, Harrison TN, et al. Dietary approaches to prevent hypertension. Curr Hypertens Rep 2013;15:694-702.

34. Ordovas JM, Ferguson LR, Tai ES, et al. Personalised nutrition and health. BMJ 2018;361:bmj.k2173.

35. Coughlin SS, Hardy D, Caplan LS. The need for culturally-tailored smartphone applications for weight control. J Ga Public Health Assoc 2016;5:228-32.

36. Hasan M, Singh H, Haffizulla F. Culturally Sensitive Health Education in the Caribbean Diaspora: A Scoping Review. Int J Environ Res Public Health 2021;18:1476.

37. Nordström K, Coff C, Jönsson H, et al. Food and health: individual, cultural, or scientific matters? Genes Nutr 2013;8:357-63.

38. KPMG in India and Google. Indian Languages - Defining India's Internet. India, 2017. Available online: https:// assets.kpmg/content/dam/kpmg/in/pdf/2017/04/Indianlanguages-Defining-Indias-Internet.pdf

39. Boulos MN, Brewer AC, Karimkhani C, et al. Mobile medical and health apps: state of the art, concerns,

doi: $10.21037 /$ mhealth-21-25

Cite this article as: Kaur M, Kaur H, Rathi S, Ashwitha M, Joanna J, Reddy S, Idris B, Myrtle P, Kandamuru S, Fatima S, Joshi A. Apps on Google Play Store to assist in self-management of hypertension in Indian context: features analysis study. mHealth 2022;8:14. regulatory control and certification. Online J Public Health Inform 2014;5:229.

40. Biviji R, Vest JR, Dixon BE, et al. Factors Related to User Ratings and User Downloads of Mobile Apps for Maternal and Infant Health: Cross-Sectional Study. JMIR Mhealth Uhealth 2020;8:e15663.

41. Kotz D, Gunter CA, Kumar S, et al. Privacy and Security in Mobile Health: A Research Agenda. Computer (Long Beach Calif) 2016;49:22-30.

42. Overdijkink SB, Velu AV, Rosman AN, et al. The Usability and Effectiveness of Mobile Health Technology-Based Lifestyle and Medical Intervention Apps Supporting Health Care During Pregnancy: Systematic Review. JMIR Mhealth Uhealth 2018;6:e109.

43. Schmidt-Kraepelin M, Thiebes S, Sunyaev A. Investigating the Relationship between User Ratings and Gamificationa Review of Mhealth Apps in the Apple App Store and Google Play Store. 2019. Maui, HI, USA: 52nd Hawaii International Conference on System Sciences.

44. Muessig KE, Pike EC, Legrand S, et al. Mobile phone applications for the care and prevention of HIV and other sexually transmitted diseases: a review. J Med Internet Res 2013;15:e1.

45. Carlo AD, Hosseini Ghomi R, Renn BN, et al. By the numbers: ratings and utilization of behavioral health mobile applications. NPJ Digit Med 2019;2:54.

46. Plante TB, O'Kelly AC, Macfarlane ZT, et al. Trends in user ratings and reviews of a popular yet inaccurate blood pressure-measuring smartphone app. J Am Med Inform Assoc 2018;25:1074-9.

47. Google. Add preview assets to showcase your app 2021. Available online: https://support.google.com/googleplay/ android-developer/answer/9866151?hl=en 